\title{
Course of COPD assessment test (CAT) and clinical COPD questionnaire (CCQ) scores during recovery from exacerbations of chronic obstructive pulmonary disease
}

\author{
Marc Miravitlles ${ }^{1 *}$, Patricia García-Sidro², Alonso Fernández-Nistal ${ }^{3}$, María Jesús Buendía ${ }^{4}$,
} María José Espinosa de los Monteros ${ }^{5}$ and Jesús Molina ${ }^{6}$

\begin{abstract}
Introduction: COPD exacerbations have a negative impact on lung function, decrease quality of life (QoL) and increase the risk of death. The objective of this study was to assess the course of health status after an outpatient or inpatient exacerbation in patients with COPD.

Methods: This is an epidemiological, prospective, multicentre study that was conducted in 79 hospitals and primary care centres in Spain. Four hundred seventy-six COPD patients completed COPD assessment test (CAT) and Clinical COPD Questionnaire (CCQ) questionnaires during the 24 hours after presenting at hospital or primary care centres with symptoms of an exacerbation, and also at weeks 4-6. The scores from the CAT and CCQ were evaluated and compared at baseline and after recovery from the exacerbation.

Results: A total of 164 outpatients (33.7\%) and 322 inpatients (66.3\%) were included in the study. The majority were men (88.2\%), the mean age was 69.4 years $(\mathrm{SD}=9.5)$ and the mean FEV1 (\%) was $47.7 \%(17.4 \%)$. During the exacerbation, patients presented high scores in the CAT: [mean: $22.0(\mathrm{SD}=7.0)$ ] and the CCQ: [mean: $4.4(\mathrm{SD}=1.2)$ ]. After recovery there was a significant reduction in the scores of both questionnaires [CAT: mean: $-9.9(S D=5.1)$ and CCQ: mean: - $3.1(S D=1.1)$ ]. Both questionnaires showed a strong correlation during and after the exacerbation and the best predictor of the magnitude of improvement in the scores was the severity of each score at onset.
\end{abstract}

Conclusions: Due to their good correlation, CAT and CCQ can be useful tools to measure health status during an exacerbation and to evaluate recovery. However, new studies are necessary in order to identify which factors are influencing the course of the recovery of health status after a COPD exacerbation.

Keywords: COPD, Health status, CAT, CCQ, Exacerbations

\section{Introduction}

Chronic Obstructive Pulmonary Disease (COPD) is a major cause of death in industrialized countries. The mortality rate of this disease is increasing and it is likely to become the third leading cause of death worldwide in $2020[1,2]$. COPD is often aggravated by acute periods of increased symptoms called exacerbations. These are the

\footnotetext{
*Correspondence: mmiravitlles@vhebron.net

'Pneumology Department, Hospital Universitari Vall d'Hebron, Ciber de Enfermedades Respiratorias (CIBERS), Barcelona, Spain

Full list of author information is available at the end of the article
}

most common reason for doctor's visits, emergency department visits, hospital admissions and deaths [3].

In addition, numerous studies have shown that exacerbations generate a large impact on health systems $[3,4]$. For example, they cause $10-12 \%$ of primary care visits, $1-2 \%$ of emergency room visits and $10 \%$ of hospitalizations in Spain [4]. This is why, from an economic standpoint, these data are of particular relevance since $44 \%$ of the annual cost per patient involving COPD is due to hospital admissions, exacerbations being the most frequent cause [5].

Among many other aspects, exacerbations are associated to a deterioration in the patients' quality of life [6]. 
However, studies that have focused on determining the evolution of a patient after suffering an exacerbation are mainly based on investigating functional $[7,8]$ or inflammatory changes [9-11].

Certain generic quality-of-life questionnaires such as the EuroQol Five-Dimensional Questionnaire (EQ-5D) [12], or respiratory-specific questionnaires such as the St. George's Respiratory Questionnaire (SGRQ) [13], may be useful to assess the recovery of patients who have suffered an exacerbation. However, the usefulness of the most widely used short questionnaires, the COPD Assessment Test (CAT) [14] and the Clinical COPD Questionnaire (CCQ) [15] to assess the course of moderate or severe exacerbations has not been investigated adequately. These two questionnaires have the great advantage of simplicity for the patient, both having a very good correlation with the SGRQ [14-16], considered the gold standard of specific health-related quality-of- life (HRQoL) questionnaires for COPD.

In this work we present the results of the course of CAT and CCQ scores during the recovery of an acute exacerbation of COPD and the factors associated to the changes in scores of patients recovering from these episodes, as well as the comparison and correlation between both instruments.

\section{Method}

\section{Study design}

The ECO study (Exacerbations and quality of life in COPD) was an observational, multicentre, prospective study aimed at evaluating the predictive value of different HRQoL questionnaires in the long-term course of patients measured as time to the next exacerbation or death. In order for the study to be feasible, we selected a population of patients after recovery from an exacerbation, because these subjects are more likely to suffer a second episode during follow-up [17]. Patients were recruited upon presentation at the hospital or at primary care offices with symptoms of an exacerbation. Those who met inclusion and exclusion criteria were informed about the study and were asked to sign an informed consent document. The physicians in charge collected information upon presentation or during the first 24 hours after admission. This information included demographic data, as well as data related to smoking, medical history and comorbidities. The cardiovascular risk was assessed according to BMI, gender and waist circumference [18]. Patients were asked to fill in COPD assessment test (CAT) and Clinical COPD Questionnaire (CCQ) quality-of-life questionnaires in their validated versions in Spanish.

The patients were evaluated again after 4 to 6 weeks from the initial visit, at which point they filled out both questionnaires once more. For the study, only those patients who recovered from the exacerbation during that time frame were followed up for time to next exacerbation or for death and they comprise the population of this analysis. The investigator had to verify clinical recovery; in addition, patients had to answer "somewhat better" or "much better" to a question about their health status: "In relation to the previous visit, how are you?" using a 5point Likert scale with the following response options: "Much worse, worse, same, better, much better. "Furthermore, the CAT score must have improved by at least 5 units to consider that the patient had recovered from the exacerbation [19].

Moderate COPD exacerbations were defined as a sudden increase in respiratory symptoms that required ambulatory treatment with systemic corticosteroids and/or antibiotics, and exacerbations were considered severe when the patient required hospitalization.

The study was approved by the ethics committee of the Hospital Clinic (Barcelona, Spain. Reference number 2012/5918) and all participants provided a written informed consent.

\section{Population}

Patients of both genders, aged 40 years or older, were recruited in the study if they met the following inclusion criteria: a) COPD demonstrated by spirometry performed in stable state not more than 12 months before being recruited in the study with a post-bronchodilator ratio of FEV1/FVC < 0.7; b) smoker or former smoker of at least 10 pack-years; c) exacerbation defined as an increase in respiratory symptoms that requires treatment with systemic corticosteroids, antibiotics or both, and/or hospitalisation. On the other hand, the exclusion criteria in the study were: (i) patients with another chronic respiratory disease (e.g. bronchial asthma, cystic fibrosis, severe bronchiectasis, cancer, restrictive lung disease, etc.), (ii) patients with a COPD exacerbation due to other causes such as pneumonia, pneumothorax and decompensated congestive heart failure, (iii) patients requiring invasive or non-invasive mechanical ventilation (iv) patients who, in the opinion of the investigator, did not retain sufficient cognitive capacity, presenting sensory or psychiatric disability or language barriers that prevent or hinder a normal conduction of the study, (v) patients participating in another study or clinical trial.

\section{Measurements}

The CAT consists of 8 items with scores ranging from 0 to $5(0=$ no impairment $)$. An overall score is calculated by adding the score from each item with total scores ranging from 0 to 40 , higher scores indicating a more severe health status impairment or a poorer control of COPD [16]. The CAT's minimal clinical important difference (MCID) is not yet established and has been estimated at 3.76 points [20]. The CCQ has three domains: symptoms ( 4 items), functional status ( 4 items) and 
mental state (2 items), graded on a 7-point Likert scale from 0 to $6(0=$ no impairment $)$ [14]. The MCID has been established at 0.41 points [21].

For the collection of information, a web-based form (e-CRF) has been designed specifically for this study.

\section{Statistical analysis}

In order describe the qualitative variables, absolute frequencies and percentages were used; furthermore, for ordinal qualitative variables, cumulative frequencies and percentages were used. The description of quantitative variables was performed using the mean, standard deviation (SD), median and quartiles. A comparison of qualitative variables between two or more groups was performed using the chi-square test and/or Fisher's exact test. A comparison of quantitative variables between two groups was performed using the Mann-Whitney U test or Student's t test, depending on the distribution of the data. A comparison of quantitative variables between three or more groups was carried out using the Kruskall Wallis test or ANOVA, depending on the distribution of the data. The results of the analysis were adjusted by the techniques of Oldham and Blomqvist. The correlation between quantitative variables was performed using the Pearson correlation coefficient; a correlation was considered good when the $\mathrm{R}$ coefficient was higher than 0.7 and acceptable between 0.5 and 0.7 .

We developed two regression models to determine the factors that could best explain the change in score in each of the questionnaires from the time of exacerbation until recovery. Due to the non-normal nature of the variable obtained for change in scores (recovery-exacerbation) for CAT, it was decided to analyse this variable as categorical by means of logistic regression analysis, divided into tertiles of change: improvement of 5-6 points; improvement of 7-12 points and improvement of more than 12 points. A linear regression analysis model for change in the CCQ was developed taking into account the variable as quantitative. Univariate analyses were carried out without considering an intercept in the model, since each intercept would vary depending on the type of each variable (e.g., there is no estimate of a mean population probability of intensity change in the CAT, but all the variability depends on the value of the dependent variable). The multivariate model, however, in addition to adjusting for the variables of the model, includes an intercept. For the analysis we used the SAS Enterprise Guide 4.3. (SAS v.9.2)

\section{Results}

\section{Patient population}

A total of 675 patients were recruited in the study. Of these, 45 were lost to follow-up, 39 did not meet inclusion or exclusion criteria, 28 did not recover from the exacerbation by 4 to 6 weeks and 77 were excluded due to insufficient information for analysis, leaving 486 (72\%) eligible patients. The demographic characteristics of the patients are shown in Table 1 . One hundred sixtyfour $(33.7 \%)$ were outpatients and $322(66.3 \%)$ were inpatients. The majority were men $(88.2 \%)$, the mean age was 69.4 years $(\mathrm{SD}=9.5)$ and the mean FEV1 (\%) was $47.7 \%(17.4 \%)$. Compared with outpatients, inpatients had a lower BMI, a longer smoking history and a lower cardiovascular risk. Regarding COPD, these patients had a longer history of the disease, as well as a greater number of exacerbations reported in the previous year and more severe lung function impairment as shown by spirometry.

\section{Changes in health status}

At the time of exacerbation, the patients had high scores on the CAT: [22.0 (SD = 7.0)], with differences between inpatients $[22.8(\mathrm{SD}=7.0)]$, and outpatients [20.4 $(\mathrm{SD}=$ 6.9)]. After recovery, there was a significant reduction of $9.9(\mathrm{SD}=5.1)$ points. Improvements were significant in both inpatients and outpatients $[8.9(\mathrm{SD}=4.6)$ and 10.4 $(\mathrm{SD}=5.3)$ respectively; $\mathrm{p}<0.001$ for both groups], (Table 2 , Figure 1).

Regarding the CCQ, the patients experienced a statistically significant improvement in the global scale after recovery, from a score of 4.4 points $(S D=1.2)$ at the time of exacerbation to 3.1 points $(\mathrm{SD}=1.1)$ once stabilized. This improvement occurred similarly in outpatients and inpatients $[1.0(\mathrm{SD}=0.9)$ and $1.4(\mathrm{SD}=1.0)$, respectively; $\mathrm{p}<0.001$ for both groups], and in all areas of the questionnaire, but particularly in the symptoms score (difference $=-1.6$ points $(\mathrm{SD}=0.7) ; \mathrm{p}<0.001) \quad$ (Table 2 , Figure 2).

\section{Correlation between the questionnaires}

Whatever the type of exacerbation (outpatient/inpatient), there was a good correlation between the CAT scores and the CCQ scores, both at exacerbation onset $(R=0.748$; $\mathrm{p}<0.0001$ ) (Figure 3), and once the patient had recovered $(R=0.780 ; p<0.001)$ (Figure 4). Furthermore, there was an acceptable correlation between the change (exacerbation-recovery) scores in both questionnaires $(\mathrm{R}=0.594 ; \mathrm{p}<0.0001)$ (Figure 5).

\section{Predictors of changes in health status}

After performing the logistic regression analysis, it was observed that the variation in the CAT scoring between exacerbation onset and recovery was greatly dependent on the score at exacerbation onset. Thus, there was a greater improvement for patients who began with the worse initial status [OR (95\% CI): 0.84 (0.81 to 0.86$)$, $\mathrm{p}<0.001$ ]. In this model, the outcome variable (change in CAT score) was categorised into 3 categories and the 
Table 1 Demographic and clinical characteristics

\begin{tabular}{|c|c|c|c|c|}
\hline Variable & $\begin{array}{c}\text { Total } \\
\mathrm{N}=486\end{array}$ & $\begin{array}{l}\text { Ambulatory } \\
\mathrm{N}=164\end{array}$ & $\begin{array}{l}\text { Hospital } \\
\mathrm{N}=322\end{array}$ & $p$ value \\
\hline Sex, male & $432(88.9)$ & $138(84.2)$ & $294(91.3)$ & 0.022 \\
\hline Age, years & $69.4(9.5)$ & $69.5(9.1)$ & $69.3(9.7)$ & 0.91 \\
\hline $\mathrm{BMl}, \mathrm{Kg} / \mathrm{m} 2$ & $27.8(9.7)$ & $29.4(14.9)$ & $26.9(5.1)$ & $<0.001$ \\
\hline Active smokers & $139(28.6)$ & $49(29.9)$ & $90(28)$ & 0.65 \\
\hline Smoking habit, pack/years & $54.5(30.5)$ & $48.9(28.9)$ & $57.3(30.9)$ & 0.004 \\
\hline \multicolumn{5}{|l|}{ Level of education } \\
\hline No school & $117(24.1)$ & $22(13.4)$ & $95(29.5)$ & $<0.001$ \\
\hline Primary education & $245(50.4)$ & $93(56.7)$ & $152(47.2)$ & \\
\hline Secondary/higher education & $124(25.5)$ & $49(29.9)$ & $75(23.3)$ & \\
\hline \multicolumn{5}{|l|}{ Cardiovascular risk } \\
\hline None & $123(25.3)$ & $28(17.0)$ & $95(29.5)$ & 0.009 \\
\hline Increased & $128(26.3)$ & $45(27.4)$ & $83(25.8)$ & \\
\hline High & $115(23.7)$ & $39(23.8)$ & $76(23.6)$ & \\
\hline Very high & $120(24.7)$ & $52(31.7)$ & $68(21.1)$ & \\
\hline Diabetes mellitus & $127(26.1)$ & $41(25.0)$ & $86(26.7)$ & 0.68 \\
\hline Waist circumference, $\mathrm{cm}$ & $99.2(18.7)$ & $101.3(14.7)$ & $98.1(20.4)$ & $<0.001$ \\
\hline Time walking per day, minutes & $55.0(26.0)$ & $68.2(32.3)$ & $48.08(24.2)$ & $<0.001$ \\
\hline Time of COPD evolution, years & $9.9(8.3)$ & $8.6(7.4)$ & $10.6(8.6)$ & 0.013 \\
\hline Number of exacerbations previous year & $2.9(2.7)$ & $2.4(1.9)$ & $3.2(2.9)$ & 0.002 \\
\hline$\overline{F V C, m L}$ & $2549.1(795.9)$ & $2930.9(864.8)$ & $2357.0(683.0)$ & $<0.001$ \\
\hline FVC, \% & $68.1(17.5)$ & $76.3(16.1)$ & $64.0(16.7)$ & $<0.001$ \\
\hline FEV1, mL & $1312.9(523.8)$ & $1658.9(534.9)$ & $1138.8(422.5)$ & $<0.001$ \\
\hline FEV1, \% & $47.7(17.4)$ & $59.3(16.2)$ & $41.8(14.9)$ & $<0.001$ \\
\hline FEV1/FVC, \% & $51.4(11.7)$ & $56.9(9.8)$ & $48.7(11.6)$ & $<0.001$ \\
\hline
\end{tabular}

Values are expressed as mean (standard deviation) or frequency (\%).

Footnote: BMI Body Mass Index.

OR indicates the odds to move from each category to the next. Nevertheless, the adjusted model can only explain $32.4 \%$ of the variance (Table 3 ).

Regarding the CCQ, the resulting model explains $30.8 \%$ of the variability. The improvement in CCQ scores at recovery from exacerbation is greater when: there is a higher baseline CCQ score [ $\beta$ (95\% CI): -0.46 $(-0.52$ to -0.40$) ; \mathrm{p}<0.001]$, fewer total exacerbations in the past year [ $\beta$ (95\% CI): 0.04 (0.01 to 0.07$) ; p=0.007]$ and the patient is not living with smokers $[\beta(95 \% \mathrm{CI})$ : $0.25(-0.44$ to -0.06$) ; \mathrm{p}=0.01$ ] (Table 4$)$.

\section{Discussion}

The results of the current study have demonstrated there is a severe impairment in the health status of exacerbated patients, both in inpatient and outpatient settings. As expected, scores of both questionnaires were significantly worse in admitted compared with ambulatory patients. The patients who recovered from the acute episode showed a highly significant improvement in the scores of the CAT and the CCQ. Furthermore, there was a good correlation of the scores of both questionnaires at exacerbation onset and at recovery. The best predictor of the magnitude of the improvement in scores of both questionnaires is the score of the given questionnaire at exacerbation onset. These results suggest that both questionnaires can be used in a clinical setting to evaluate the improvement in health status during and/or after the treatment of a moderate or severe exacerbation of COPD.

The CAT questionnaire has shown to provide significantly different scores in stable and exacerbated patients in cross-sectional studies. Jones et al. [22], in a validation study, reported a mean score of 17.2 points in stable COPD patients compared with 21.3 in exacerbated COPD patients. Agustí et al. [23] obtained a score of 22.4 points in a group of COPD inpatients compared with 15.8 in stable patients. Interestingly, we obtained an almost identical CAT score in our inpatients (22.8 points), which was significantly reduced to only 12.4 after recovery from the acute episode. This large improvement in CAT scores after an admission is similar to the one reported by the previous group of investigators in patients who claimed to feel "much better" after recovery from the hospitalization (8.9 units) [13]. When analysing the data in the opposite 
Table 2 Course of health status, CAT and CCQ test scores

\begin{tabular}{lcccc}
\hline Questionnaire & Exacerbation & Recovery & Change (R-E) & P value \\
\hline CAT total & & & & \\
\hline Total & $22.0(7.0)$ & $12.1(5.9)$ & $-9.9(5.1)$ & $<0.001$ \\
\hline Outpatient & $20.4(6.9)$ & $11.5(5.8)$ & $-8.9(4.6)$ & $<0.001$ \\
\hline Inpatient & $22.8(7.0)$ & $12.4(6.0)$ & $-10.4(5.3)$ & $<0.001$ \\
\hline CCQ total & & & & \\
\hline Total & $4.4(1.2)$ & $3.1(1.1)$ & $-1.3(0.9)$ & $<0.001$ \\
\hline Outpatient & $3.8(1.2)$ & $2.8(1.0)$ & $-1.0(0.9)$ & $<0.001$ \\
\hline Inpatient & $4.6(1.1)$ & $3.2(1.1)$ & $-1.4(1.0)$ & $<0.001$ \\
\hline CCQ; symptoms & & & & \\
\hline Total & $4.7(1.3)$ & $3.1(1.1)$ & $-1.6(0.7)$ & $<0.001$ \\
\hline Outpatient & $4.4(1.3)$ & $3.1(1.1)$ & $-1.3(0.9)$ & $<0.001$ \\
\hline Inpatient & $4.9(1.2)$ & $3.1(1.1)$ & $-1.8(1.0)$ & $<0.001$ \\
\hline CCQ: functional & & & & \\
\hline Total & $4.1(1.4)$ & $3.1(1.3)$ & $-1.0(1.2)$ & $<0.001$ \\
\hline Outpatient & $3.4(1.3)$ & $2.6(1.1)$ & $-0.8(0.5)$ & $<0.001$ \\
\hline Inpatient & $4.5(1.3)$ & $3.3(1.3)$ & $-1.2(0.7)$ & $<0.001$ \\
\hline CCQ: mental & & & & \\
\hline Total & $4.1(1.5)$ & $2.9(1.4)$ & $-1.2(1.1)$ & $<0.001$ \\
\hline Outpatient & $3.6(1.5)$ & $2.7(1.3)$ & $-0.9(0.9)$ & $<0.001$ \\
\hline Inpatient & $4.4(1.5)$ & $3.1(1.4)$ & $-1.3(1.1)$ & $<0.001$ \\
\hline Values are expressed as mean points (standard deviation). & & & \\
& & & & \\
\hline
\end{tabular}

direction (from stable state to exacerbation) MacKay et al. [19] noted a change from 19.4 to 24.1 points in the CAT score in a population of outpatients with COPD. This change was smaller in magnitude to the one observed in our study, but the health status impairment of those patients was more severe than that observed in our population $(\mathrm{CAT}=12.1$ at recovery). Another difference is that return to baseline in the aforementioned study was considered at 11 days, in contrast to 4 to 6 weeks in our study. Previous studies using the SGRQ suggested that the health

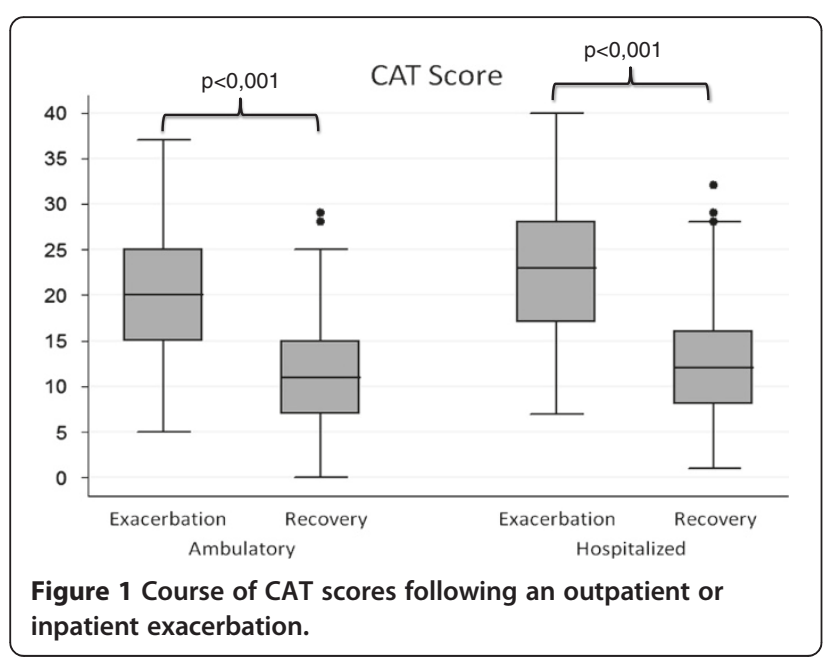

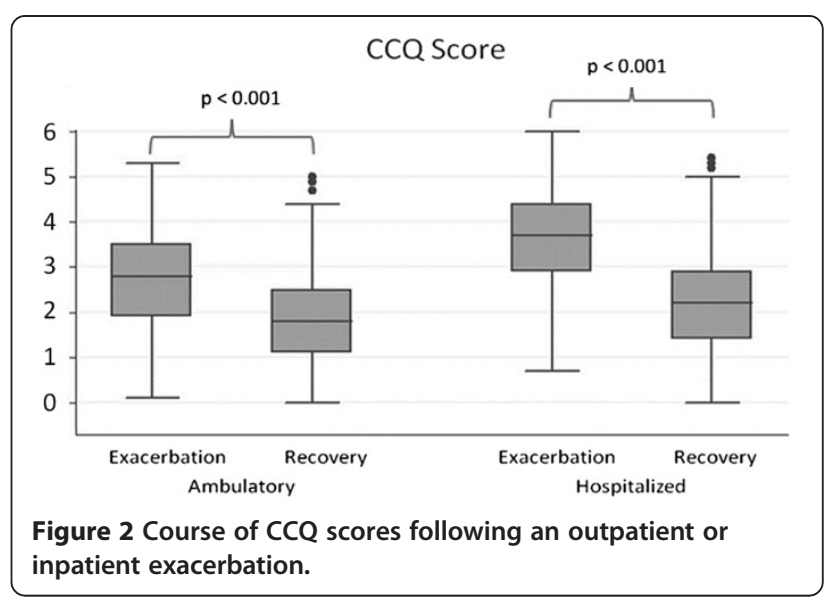

status may require up to 12 weeks to full recovery [13]. Despite of these results, we have to take into consideration the fact that CAT has not been validated for determining the severity of an exacerbation. In fact, some subjects included in the Mackay [19] study had a decline in the CAT score when they suffered an exacerbation, while others had no significant changes. Questionnaires designed specifically to assess the changes in health status during exacerbations such as the EXAcerbations of Chronic Obstructive Pulmonary Disease Tool (EXACT) can be more useful for quantifying the severity of these events [24].

In addition, it must be noted that due to the design of the study, we only considered those patients who recovered from the exacerbation and one of the criteria for recovery was an improvement of at least 5 points in CAT scores. Therefore, we cannot analyse the validity of the questionnaires to identify patients who could fail in the treatment of an exacerbation. However, only 28 patients (4.2\%) could not be recruited in the study because they did not reach this threshold at recovery.

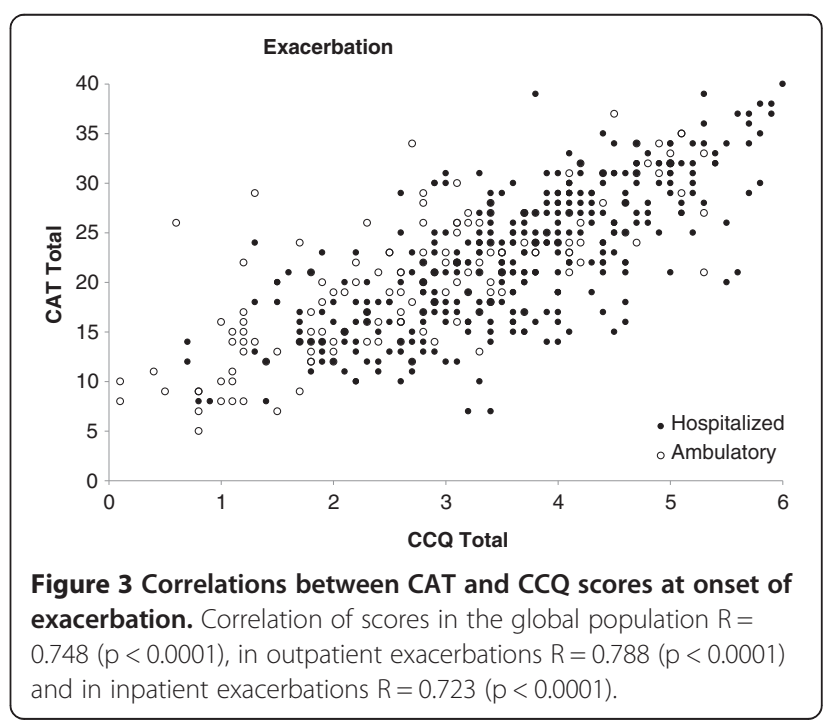




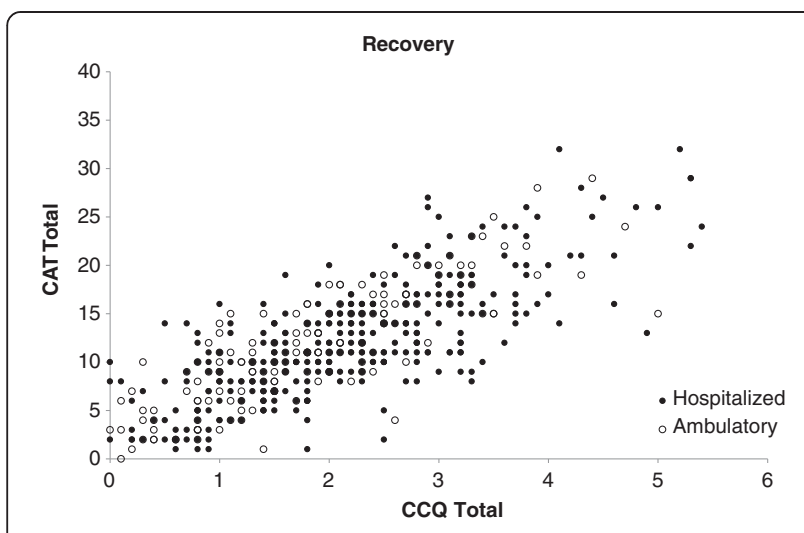

Figure 4 Correlations between CAT and CCQ scores after recovery from the exacerbation. Correlation of scores in the global population $R=0.780(p<0.0001)$, in outpatient exacerbations $R=0.827(p<0.0001)$ and in inpatient exacerbations $R=0.760(p<0.0001)$.

Regarding the CCQ, we noted a mean reduction of -1.3 points at recovery, which was even higher for the symptoms scale $(-1.6$ points) and clearly higher than the suggested clinically significant minimum difference of 0.41 [20]. In a previous cross-sectional study on 3,935 COPD patients in Spain, the mean value of CCQ was 2.5 and it was significantly associated to the degree of dyspnoea, the frequency of previous exacerbations and hospitalizations, the severity of FEV1 impairment and a low level of education and physical activity [25]. However, longitudinal data of CCQ during recovery from exacerbations is limited. In contrast, an improvement in total scores of around 0.50 points has been observed after quitting smoking (improvement of 1.02 points in symptoms) [14,26]. The CCQ scores have been used for monitoring patients to predict treatment failure or the occurrence of an exacerbation. Using weekly measurements, an impairment of 0.20 points

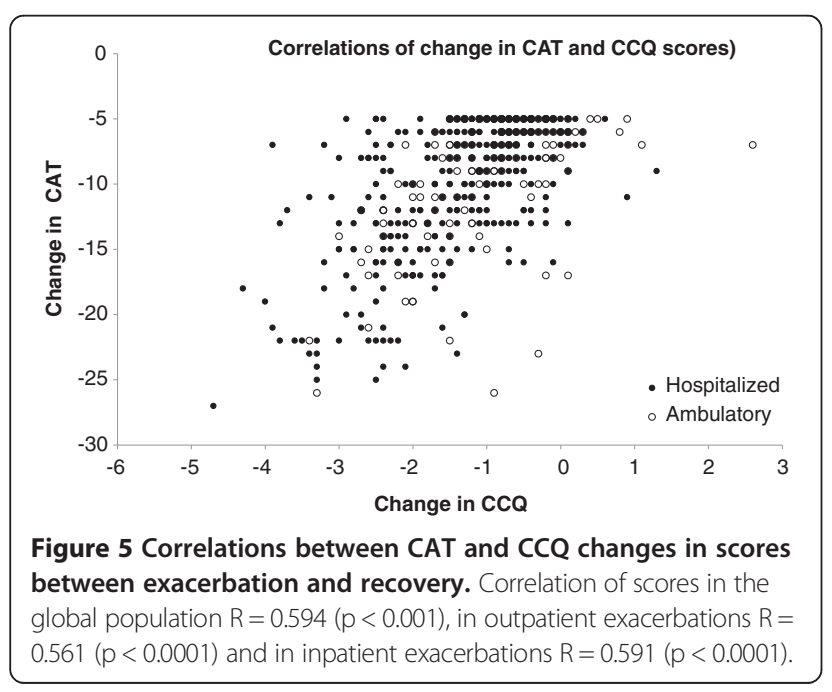

had a positive predictive value of $43.5 \%$ and a negative predictive value of $90.8 \%$ for the onset of an exacerbation in the next week [27]. Furthermore, a recent work in which the patients were monitorised daily during an exacerbation, showed that the absence of improvement in CCQ symptoms score and impaired lung function were independent predictors of treatment failure [28]. Concurrent with our results, the authors find the rate and pattern of recovery very similar in outpatients and inpatients [28].

Similarly to CAT, the best predictor of a large improvement in CCQ score after recovery was a worse score at exacerbation onset. A regression to the mean effect cannot be ruled out; however, for the improvement in CCQ scores other variables showed a significant and independent association with the magnitude of change. The patients who experienced fewer exacerbations in the past had a higher improvement in CCQ scores, as did those who lived with smokers. The relationship between repeated exacerbations and impairment in HRQoL has been noted in numerous studies $[6,29]$, and was seen consistently with our results; a previous study demonstrated that patients who suffered repeated exacerbations did not revert to the baseline values of health status after an exacerbation [13]. The relationship between a higher improvement in CCQ scores and living with smokers is difficult to account for and might be related with worse scores at onset because more severe symptoms associated to second hand smoke, but this hypothesis should be tested adequately. However, only a small part of the variance has been explained by the variables included in the regression models. Other factors not addressed in our study may influence the recovery of these patients. For instance, Papaioannou et al. [30] observed that depressive symptoms had a negative effect on CAT improvement during recovery from an exacerbation.

The difference between the predictors of recovery found for CAT and CCQ can be explained in part by the different types of analysis; however, there are also some differences between them. CAT is a one-dimensional questionnaire, in turn, CCQ has different domains that correlate better with the corresponding SGRQ domains [20]. Furthermore, CCQ has been validated to be used at the level of individual patients [31].

More interesting and unique in our results was the relationship between the scores of both questionnaires. We have demonstrated a good correlation of the scores of CAT and CCQ at exacerbation onset and at recovery and also an acceptable correlation of the changes in scores observed in both questionnaires after recovery. These results suggest that both are measuring the same effects and that both can be used reliably in this context. To the best of our knowledge, this is the first study to compare the performance of both questionnaires during the recovery of 
Table 3 Study of univariate and multivariate association of change in CAT score from exacerbation to stable state, categorized into three categories (5-6 points, 7-12 points, and over 12)

\begin{tabular}{|c|c|c|c|c|c|c|}
\hline \multirow[t]{2}{*}{ Variable } & \multicolumn{3}{|c|}{ Univariate } & \multicolumn{3}{|c|}{ Multivariate } \\
\hline & OR & $95 \% \mathrm{Cl}$ & $\mathbf{P}$ & $\overline{\text { OR }}$ & $95 \% \mathrm{Cl}$ & $\mathbf{P}$ \\
\hline Type of exacerbation (inpatient vs. outpatient RC) & 2.3 & 1.6 to 3.2 & $<0.001$ & & & \\
\hline Gender (men vs. women RC) & 2.3 & 1.6 to 3.3 & 0.051 & & & \\
\hline Waist circumference & 0.994 & 0.992 to 0.996 & $<0.001$ & & & \\
\hline Smoking status (current vs. former smoker RC) & 1.64 & 1.17 to 2.32 & 0.004 & & & \\
\hline Exacerbations previous year & 0.89 & 0.85 to 0.93 & $<0.001$ & & & \\
\hline FEV1 (\%) & 0.99 & 0.98 to 0.99 & $<0.001$ & & & \\
\hline CAT at inclusion & 0.96 & 0.95 to 0.97 & $<0.001$ & 0.84 & 0.81 to 0.86 & $<0.001$ \\
\hline CCQ at inclusion & 0.84 & 0.80 to 0.87 & $<0.001$ & & & \\
\hline
\end{tabular}

Independent variables: waist circumference, exacerbations in the previous year, FEV1 (\%) and CAT and CCQ at inclusion were continuous variables. The strength of the association is presented by the OR and $95 \%$ confidence interval obtained by logistic regression.

$O R$ odds ratio, $\mathrm{Cl}$ confidence interval, $\mathrm{RC}$ Reference category.

outpatient and inpatient exacerbations. The CAT and the CCQ have also demonstrated a good correlation in stable COPD; Tsiglianni et al [20] observed a rho $=0.64$ between both scores in a group of 90 stable COPD patients over three repeated measurements. Moreover, in a study of severe COPD patients referred for rehabilitation, a correlation of $\mathrm{r}=0.77$ was shown between the CAT and the CCQ [32]. These values are similar to those obtained in our patient population ranging from $r=0.72$ to $r=0.82$ for correlations between both questionnaires either at onset or at recovery from the exacerbation. These results support the use of either questionnaire in the clinical assessment of patients with COPD, as suggested in recent guidelines [33,34].

Our study has several limitations, we have only analysed the patients that recovered from an exacerbation and therefore we cannot investigate a different course of scores according to clinical outcomes. Our results describe only the course of improvement of health status after an exacerbation. Another limitation is the use of a CAT cut-off value of 5 points for defining recovery from an exacerbation. Currently, there is no well-established MCID for CAT, which is why we also used the investigator's clinical judgement and a question with a Likert scale for the patient to contribute to the definition of recovery.

One of the strengths of our study is its observational design in a large sample of patients in different settings, which allows for the extrapolation of results with a high external validity.

In summary, our results have demonstrated a severe impairment in the health status of COPD patients at exacerbation onsets, as measured by CCQ and CAT scores. Health status significantly improves during recovery. There is a strong correlation between the scores of both questionnaires at onset and at recovery and the best predictor of the magnitude of improvement is the severity of the score at onset. Both instruments can be used to monitor the course of recovery of outpatient or inpatient COPD exacerbations.

Table 4 Study of univariate and multivariate association of change in CCQ score from exacerbation to stable state

\begin{tabular}{|c|c|c|c|c|c|c|}
\hline \multirow[t]{2}{*}{ Variable } & \multicolumn{3}{|c|}{ Univariate } & \multicolumn{3}{|c|}{ Multivariate } \\
\hline & B & $95 \% \mathrm{Cl}$ & $\mathbf{P}$ & B & $95 \% \mathrm{Cl}$ & $\mathbf{P}$ \\
\hline Type of exacerbation (inpatient vs. outpatient RC) & -1.44 & -1.56 to -1.32 & $<0.001$ & & & \\
\hline Gender (men vs. women RC) & -1.27 & -1.38 to -1.17 & $<0.001$ & & & \\
\hline BMl & -0.004 & -0.008 to -0.0002 & $<0.001$ & & & \\
\hline Smoking (current vs. former-smoker RC) & 1.33 & 1.57 to 1.09 & $<0.001$ & & & \\
\hline Lives with smokers (yes vs. no RC) & 1.44 & 1.12 to 1.75 & $<0.001$ & -0.25 & -0.44 to -0.06 & 0.010 \\
\hline Exacerbations previous year & -0.25 & -0.28 to -0.22 & $<0.001$ & 0.04 & 0.01 to 0.07 & 0.007 \\
\hline FEV1 (\%) & -0.023 & -0.043 to 0.003 & $<0.001$ & & & \\
\hline CAT at inclusion & -0.057 & -0.06 to -0.05 & $<0.001$ & & & \\
\hline CCQ at inclusion & 0.84 & 0.80 to 0.87 & $<0.001$ & -0.46 & -0.52 to -0.04 & $<0.001$ \\
\hline
\end{tabular}

The CCQ score change has been studied as a continuous variable and the strength of the association occurs through the beta coefficients obtained by linear regression. BMI, exacerbations previous year FEV1 (\%) and CAT and CCQ at inclusion were continuous variables.

$B$ Beta coefficient, $C l$ confidence interval, RC Reference category. 


\section{Competing interests}

Marc Miravitlles has received speaker fees from Boehringer Ingelheim, Pfizer, AstraZeneca, Bayer Schering, Novartis, Talecris-Grifols, Takeda-Nycomed, Merck, Sharp \& Dohme and Novartis, and consulting fees from Boehringer Ingelheim, Pfizer, GSK, AstraZeneca, Bayer Schering, Novartis, Almirall, Merck, Sharp \&Dohme, Talecris-Grifols and Takeda-Nycomed. Alonso Fernández is a full time employee of Takeda. The rest of authors have no conflicts of interest to disclose.

\section{Authors' contributions}

$M M, J M$ and AFN designed the study and directed the data analysis. MM and AFN drafted the manuscript. PGS, MJB, MJEM, JM participated in data collection and critical revisión of the data analysis. All authors read and approved the final manuscript.

\section{Acknowledgments}

The study was sponsored by Takeda Farmacéutica España S.A. The authors thank Dr. Jesús Aparicio (Medical Department, Takeda Farmacéutica España) for his contribution to the design and execution of the study.

Investigators and study sites are listed below: David De La Rosa (Hospital Plató, Barcelona), María Magdalena Medinas (Hospital Joan March, Mallorca), Juan Luis Rodriguez Hermosa (Hospital Clínico San Carlos, Madrid), Luis Perez De Llano (Hospital Universitario HULA, Lugo), Berta Avilés Huertas (Hospital de Palamós, Girona), Bernardino Alcázar Navarrete (Hospital De Alta Resolución De Loja, Granada), Silvia Molina Aguilera (Hospital De Campdevànol, Girona), Javier Labayen (Hospital de Donostia, Guipuzcoa), Juan Pablo De Torres (Clínica Universidad De Navarra), Ada Luz Andreu Rodriguez (Hospital Los Arcos Del Mar Menor, Murcia), Montserrat Vendrell (Hospital Josep Trueta, Girona), Maria Jesus Buendía Garcia (Hospital Infanta Leonor, Madrid), Maria Victoria Medina Cruz (Hospital Doctor Negrín, Las Palmas de Gran Canaria), Valentin Cabriada Nuño (Hospital de Cruces, Bizkaia), Maria Jesus Mena Rodriguez (Hospital La Mancha Centro, Ciudad Real), José Calvo Bonachera (Hospital de Torrecardenas, Almeria), Lourdes Lázaro Asegurado (Hospital General Yagüe, Burgos), Jose Manuel Cifrián Martinez (Hospital Marqués De Valdecilla, Cantabria), Manuel Brufal (Hospital Virgen De Los Lirios, Alicante), Xavier Vilà (Hospital De Mataró, Barcelona), Ana Bustamante (Hospital de Sierrallana, Cantabria), Ana Pando Sandoval (Hospital Universitario Central De Asturias), Salvador Díaz Lobato (Hospital Ramon y Cajal, Madrid), María Carmen Fernández (Hospital Universitario Reina Sofía, Córdoba), Felix Del Campo Matías (Hospital Rio Hortega, Valladolid), Graciliano Estrada (Hospital De Segovia), Agustín Medina (Hospital de La Laguna, Tenerife), Marina Blanco (C. Universitario A Coruña), Ernesto Centeno (Hospital San Eloy, Bizkaia), Isaura Parente (Complexo Hospitalario De Ourense), Joan Serra (Hospital General De Vic, Barcelona), Silvia Fernández Huerga (Hospital De León), Eva Balcells (Hospital Del Mar, Barcelona), Beatriz Lara (Hospital Universitario Arnau de Vilanova, Lleida), José Alcázar Ramírez (Clínica Quirón, Málaga), Sagrario Mayoralas Alises (Hospital Moncloa, Madrid), Rosa Cordovilla Pérez (Hospital Universitario Salamanca), Ángel Ortega (Hospital General Nuestra Señora Del Prado, Toledo), Manuel Agustin Sojo (Hospital San Pedro De Alcantara, Cáceres), Gustavo Villegas (Hospital Torrecardenas, Almería), Gerardo Pérez Chica (Hospital Ciudad De Jaén), Ma Dolores Aicart Bort (CS Rafalafena, Castellón), Tertuliano Amat Sotos (CS Acacias. Alicante), Maria Teresa Almela (CS Salvador Pau, Valencia), Juan Luis Mendía (CS Ondarreta, Guipúzcoa), Isidro López (UAP Begonte, Lugo), Javier Pérez (CS Calzada 2, Asturias), Maria Angélica Molina (CS A Ponte, Ourense), Carmen Llorente (CS Villalba-Estación, Madrid), Luisa Fernanda Sidro Bou (CS De La Vall D'Uixó, Castellón), Francisco Ponce (CS Petrer I, Alicante), Carmen Vizuete (CAP Montclar, Barcelona), Carlos Ramirez (CS Salvador Allende, Valencia), Enrique Mascarós (CS Fuente De San Luis, Valencia), Luis García-Giralda (CS Murcia-Centro, Murcia), Rosario Timiraos (CS de Culleredo, A Coruña), Jesus Méndez-Cabeza (CS Torrelodones, Madrid), Alvaro Aguirre De Cárcer (CS La Ventilla, Madrid), Jose Maria Fernandez RodriguezLacin (CS Natahoyo, Asturias), Albert Brau Tarrida (CAP La Mina, Barcelona), Tomas Soler López (C.S. Zona VII, Albacete), Javier Amiama (EAP Sodupe, Bizkaia), José Paredes Saura (CAP Hostalric, Girona), Jose Ignacio Sánchez (CS Fuente San Luis, Valencia), Ramon Cervera (CS Godella, Valencia), Vicente Alfonso Corral (UGC Puerto Sur, Cádiz), Araceli Fernandez (CS Delicias Sur, Zaragoza), Olga Vicente Lopez (CS Las Rozas, Madrid), Mario Bárcena Caamaño (CS Nóvoa Santos, Ourense), Manuel Angel Gómez (CS La Alamedilla, Salamanca), Miguel Florido Rodríguez (Consultorio De Playa De Arinaga, Las Palmas de Gran Canaria), Montserrat Mas Pujol (EAP Chafarinas, Barcelona), Xavier Flor (CAP Chafarinas, Barcelona), Javier Antón Ortega (CS Repelega, Bizcaia)

\section{Author details}

'Pneumology Department, Hospital Universitari Vall d'Hebron, Ciber de Enfermedades Respiratorias (CIBERS), Barcelona, Spain. ${ }^{2}$ Pneumology Unit, Hospital De La Plana, Villarreal, Spain. ${ }^{3}$ Medical Department, Takeda Farmacéutica España S.A, Madrid, Spain. ${ }^{4}$ Pneumology Department, Hospital Universitario Infanta Leonor, Madrid, Spain. ${ }^{5}$ Pneumology Department, Hospital Universitario Virgen de la Salud, Toledo, Spain. ${ }^{6}$ Centro de Salud "Francia", Fuenlabrada, Madrid, Spain.

Received: 30 April 2013 Accepted: 29 August 2013

Published: 29 August 2013

\section{References}

1. Decramer M, Janssens W, Miravitlles M: Chronic obstructive pulmonary disease. Lancet 2012, 379:1341-1351.

2. Lozano R, Naghavi M, Foreman K, Lim S, Shibuya K, Aboyans V, et al: Global and regional mortality from 235 causes of death for 20 age groups in 1990 and 2010: a systematic analysis for the global burden of disease study 2010. Lancet 2012, 380:2095-2128.

3. Anzueto A: Impact of exacerbations on COPD. Eur Respir Rev 2010, 19:113-118.

4. Soler J, Sánchez L, Latorre M, Alamar J, Román P, Perpiñá M: The impact of COPD on hospital resources: the specific burden of COPD patients with high rates of hospitalization. Arch Bronconeumol 2001, 37:375-381.

5. Miravitlles M, Murio C, Guerrero T, Gisbert R, on behalf of the DAFNE study group: Costs of chronic bronchitis and COPD. A one year follow-up study. Chest 2003, 123:784-791.

6. Miravitlles M, Ferrer M, Pont A, Zalacain R, Alvarez-Sala JL, Masa JF, et al: Exacerbations impair quality of life in patients with chronic obstructive pulmonary disease. A two-year follow-up study. Thorax 2004, 59:387-395.

7. Parker CM, Voduc N, Aaron SD, Webb KA, O'Donnell DE: Physiological changes during symptom recovery from moderate exacerbations of COPD. Eur Respir J 2005, 26:420-428.

8. Pinto-Plata VM, Livnat G, Girish M, Cabral H, Masdin P, Linacre P, et al: Systemic cytokines, clinical and physiological changes in patients hospitalized for exacerbation of COPD. Chest 2007, 131:37-43.

9. Gompertz S, O'Brien C, Bayley DL, Hill SL, Stockley RA: Changes in bronchial inflammation during acute exacerbations of chronic bronchitis. Eur Respir J 2001, 17:1112-1119.

10. Perera WR, Hurst JR, Wilkinson TM, Sapsford RJ, Müllerova H, Donaldson GC, et al: Inflammatory changes, recovery and recurrence at COPD exacerbation. Eur Respir J 2007, 29:527-534.

11. Koutsokera A, Kiropoulos TS, Nikoulis DJ, Daniil ZD, Tsolaki V, Tanou K: Clinical, functional and biochemical changes during recovery from COPD exacerbations. Respir Med 2009, 103:919-926.

12. Goossens LM, Nivens MC, Sachs P, Monz BU, Rutten-van Mölken MP: Is the EQ-5D responsive to recovery from a moderate COPD exacerbation? Respir Med 2011, 105:1195-1202.

13. Spencer S, Jones PW, GLOBE Study Group: Time course of recovery of health status following an infective exacerbation of chronic bronchitis. Thorax 2003, 58:589-593.

14. Jones PW, Harding G, Berry P, Wiklund I, Chen WH, Leidy NK: Development and first validation of the COPD Assessment Test. Eur Respir J 2009, 34:648-654

15. van der Molen T, Willemse BW, Schokker S, ten Hacken NH, Postma DS, Juniper EF: Development, validity and responsiveness of the clinical COPD questionnaire. Health Qual Life Outcomes 2003, 28:1-13.

16. Jones PW, Quirk FH, Baveystock CM, Littlejohns P: A self-complete measure of health status for chronic airflow limitation. The St. George's respiratory questionnaire. Am Rev Respir Dis 1992, 145:1321-1327.

17. Hurst JR, Donaldson GC, Quint JK, Goldring JJ, Baghai-Ravary R, Wedzicha JA: Temporal clustering of exacerbations in chronic obstructive pulmonary disease. Am J Respir Crit Care Med 2009, 179:369-374.

18. National Heart, Lung, and Blood Institute, National Institutes of Health: The Practical Guide: Identification, Evaluation, and Treatment of Overweight and Obesity in Adults (NIH Publication No. 00-4084). October 2000, Available online: http://www.nhlbi.nih.gov/guidelines/obesity/prctgd_c.pdf.

19. Mackay AJ, Donaldson GC, Patel AR, Jones PW, Hurst JR, Wedzicha JA: Usefulness of the chronic obstructive pulmonary disease assessment test to evaluate severity of COPD exacerbations. Am J Respir Crit Care Med 2012, 185:1218-1224. 
20. Tsiligianni IG, van der Molen T, Moraitaki D, Lopez I, Kocks JW, Karagiannis K, et al: Assessing health status in COPD. A head-to-head comparison between the COPD assessment test (CAT) and the clinical COPD questionnaire (CCQ). BMC Pulm Med 2012, 12:20.

21. Kocks JW, Tuinenga MG, Uil SM, van den Berg JW, Ståhl E, van der Molen T: Health status measurement in COPD: the minimal clinically important difference of the clinical COPD questionnaire. Respir Res 2006, 7:62.

22. Jones PW, Brusselle G, Dal Negro RW, Ferrer M, Kardos P, Levy ML, et al: Properties of the COPD assessment test in a cross-sectional European study. Eur Respir J 2011, 38:29-35.

23. Agustí A, Soler JJ, Molina J, Muñoz MJ, García-Losa M, Roset M, et al: Is the CAT questionnaire sensitive to changes in health status in patients with severe COPD exacerbations? COPD 2012, 9:492-498.

24. Rennard SI, Bailey KL: Chronic obstructive pulmonary disease exacerbations: accurate and easy measurement promises much. Am J Respir Crit Care Med 2012, 185:1139-1141.

25. Izquierdo JL, Barcina C, Jiménez J, Muñoz M, Leal M: Study of the burden on patients with chronic obstructive pulmonary disease. Int $J$ Clin Pract 2009, 63:87-97.

26. Reda AA, Kotz D, Kocks JW, Wesseling G, van Schayck CP: Reliability and validity of the clinical COPD questionnaire and chronic respiratory questionnaire. Respir Med 2010, 104:1675-1682.

27. Trappenburg JC, Touwen I, de Weert-van Oene GH, Bourbeau J, Monninkhof EM, et al: Detecting exacerbations using the Clinical COPD Questionnaire. Health Qual Life Outcomes 2010, 8:102.

28. Kocks JW, van den Berg JW, Kerstjens HA, Uil SM, Vonk JM, de Jong YP, et al: Day-to-day measurement of patient-reported outcomes in exacerbations of chronic obstructive pulmonary disease. Int I Chron Obstruct Pulmon Dis 2013, 8:273-286.

29. Doll H, Miravitlles M: Quality of life in acute exacerbations of chronic bronchitis and chronic obstructive pulmonary disease: a review of the literature. Pharmacoeconomics 2005, 23:345-363.

30. Papaioannou Al, Bartziokas K, Tsikrika S, Karakontaki F, Kastanakis E, Banya W, et al: The impact of depressive symptoms on recovery and outcome of hospitalised COPD exacerbations. Eur Respir J 2013, 41:815-823.

31. Kocks JW, Kerstjens HA, Snijders SL, de Vos B, Biermann JJ, van Hengel P, et al: Health status in routine clinical practice: validity of the clinical COPD questionnaire at the individual patient level. Health Qual Life Outcomes 2010, 8:135.

32. Ringbaek $T$, Martinez $G$, Lange P: A comparison of the assessment of quality of life with CAT, CCQ, and SGRQ in COPD patients participating in pulmonary rehabilitation. COPD 2012, 9:12-15.

33. Miravitlles M, Soler-Cataluña JJ, Calle M, Molina J, Almagro P, Quintano JA, et al: Spanish COPD guidelines (GesEPOC). Pharmacological treatment of stable COPD. Arch Bronconeumol 2012, 48:247-257.

34. Vestbo J, Hurd SS, Agustí AG, Jones PW, Vogelmeier C, Anzueto A, Barnes PJ, et al: Global strategy for the diagnosis, management, and prevention of chronic obstructive pulmonary disease: GOLD executive summary. Am J Respir Crit Care Med 2013, 187:347-365.

doi:10.1186/1477-7525-11-147

Cite this article as: Miravitlles et al:: Course of COPD assessment test (CAT) and clinical COPD questionnaire (CCQ) scores during recovery from exacerbations of chronic obstructive pulmonary disease. Health and Quality of Life Outcomes 2013 11:147.

\section{Submit your next manuscript to BioMed Central and take full advantage of:}

- Convenient online submission

- Thorough peer review

- No space constraints or color figure charges

- Immediate publication on acceptance

- Inclusion in PubMed, CAS, Scopus and Google Scholar

- Research which is freely available for redistribution

Submit your manuscript at www.biomedcentral.com/submit
Ciomed Central 